https://www.journal-imab-bg.org

Original article

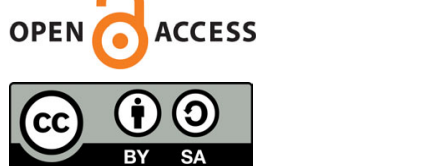

\title{
CHROMOSOMAL ABNORMALITIES AND Y CHROMOSOME MICRODELETIONS IN BULGARIAN MALE WITH AZOOSPERMIA OR SEVERE OLIGOSPERMIA
}

\author{
Katya Kovacheva ${ }^{1}$, Rumen Kotsev ${ }^{2}$, Emiliana Konova ${ }^{3}$, Violeta Rilcheva ${ }^{3}$, \\ Zornitsa Kamburova ${ }^{1}$, Maria Simeonova ${ }^{1}$ \\ 1) Section of Medical Genetics, Medical University, Pleven, University Hospital, \\ Pleven, Bulgaria. \\ 2) Clinic of Urology, University Hospital, Medical University, Pleven, Bulgaria. \\ 3) MC CIRM, Pleven, Bulgaria.
}

\section{SUMMARY}

Male infertility is a complex disease, and genetic abnormalities are among the main causal factors for the disorder. Aim: In order to evaluate the proportion of the most common genetic factors in etiology of male infertility, examination for chromosomal abnormalities and microdeletions of Yq chromosome (delYq) was carried out in Bulgarian males with severe infertility.

Materials and methods: The study was retrospective and involved a total of 142 infertile Bulgarian males (63 patients with azoospermia and 79 patients with severe oligozoospermia /sperm count $<5 \times 10^{6} / \mathrm{ml}$ ), referred (20072016) for genetic testing, after preliminary examinations to exclude some more frequent causes for male infertility. Cytogenetic analysis by GTG-banding was carried out in 137 men, and molecular testing for AZF region microdeletions of Y chromosome by multiplex PCR was carried out in 109 men.

Results: Chromosomal abnormalities were found in $16.8 \%$ of all investigated infertile men and the frequencies in patient subgroups with azoospermia and oligozoospermia were $20.7 \%(12 / 58)$ and $13.9 \%(11 / 79)$ respectively. The established frequency of delYq was $5.5 \%(6 / 109)$ in the overall group of infertile male and higher - 9.5\% (6/ 63 ) in a subgroup of patients with azoospermia.The overall proportion of the two genetic factors was $30.2 \%$ in patients with azoospermia and $14 \%$ in men with oligozoospermia. In conclusion, chromosomal abnormalities and delYq account for about $22 \%$ of cases with severe infertility in Bulgarian men. Genetic testing should be a routine part of examinations in infertile males and along with genetic counseling; they provide an opportunity for the best choice of an appropriate technique for assisted reproduction of the couples.

Keywords: male infertility, genetic causes, chromosomal abnormalities, Y chromosome microdeletions

\section{INTRODUCTION}

Infertility is a global health problem affecting 10$15 \%$ of couples at reproductive age and in half of these cases, a male causal factor can be identified [1-5]. It is estimated that about $7 \%$ of all men have problems with their fertility [6]. Male infertility is a complex disease, and several factors have been involved in etiology of the disorder: endocrine abnormalities, infections, environmental exposure, genetic defects and others. However, in $30-40 \%$ of these cases, no specific cause could be found $[1,4]$.

Genetic abnormalities are thought to play an important role in multifactorial etiology of the disorder, accounting for $10-15 \%$ of severe male infertility, including chromosomal aberations and single gene mutations $[3,6]$. Among genetic disorders are hypogonadotropic hypogonadism, mutations in the androgen receptor, cystic fibrosis gene mutations, genetic polymorphisms and $\mathrm{Y}$ chromosome linked infertility. Chromosomal anomalies are the most common genetic causes of male infertility found about 10 times more frequently in infertile men (4-16\%) than in the general population $(0.4 \%)$ [4,6]. The microdeletions of azoospermia factor (AZF) region in the $\mathrm{Y}$ chromosome are considered as the most frequent known molecular-genetic cause of severe impairment of spermatogenesis, detected in about $10 \%$ of men with non-obstructive azoospermia and $3-5 \%$ of men with idiopatic severe oligozoospermia [6].

Aim: In order to evaluate the proportion of the most common genetic defects in etiology of severe male infertility we investigated the frequency of chromosomal abnormalities and $\mathrm{Y}$ chromosome microdeletions in Bulgarian males with azoospermia or severe oligozoospermia.

\section{MATERIAL AND METHODS \\ Patients}

The current study was retrospective, based on the data of the Section of Medical Genetic, Medical University of Pleven (for the period 2007-2016) and included men with infertility, candidates for ART, referred for genetic counseling and genetic testing after preliminary examina- 
tions to exclude some more frequent causes for male infertility disorders (systemic diseases, exogenous factors, endocrine abnormalities, infections, varicocele, cryptorchidisum, erectile and other urological abnormalities). A total of 142 Bulgarian males with severe infertility (63 patients with non-obstructive azoospermia and 79 patients with severe oligozoospermia /sperm count $<5 \times 10^{6} \%$ $\mathrm{ml}$ ) were selected and included in the study. Cytogenetic analysis was carried out in 137 men (58 patients with azoospermia and 79 patients with severe oligozoospermia ). Molecular screening of AZF region microdeletions of $\mathrm{Y}$ chromosome was carried out in 109 men (63 patients with azoospermia and 46 patients with severe oligozoospermia). Both karyotyping and molecular analysis were performed in 104 men (58 with azoospermia and 46 with oligozoospermia). Written informed consent from each patient was obtained.

\section{Chromosomal analysis}

Cytogenetic study via conventional GTG- banding was carried out on phyto-haemaglutinin stimulated peripheral blood lymphocytes with analysis of at least 30 metaphases/per individual (resolution of 400-550 band/ haploid set). The detected chromosomal abnormalities (CA) were reported in accordance with ISCN, 2009.

\section{Molecular analysis}

The study of Yq chromosome microdeletions (delYq) was performed by multiplex PCR using primers for amplification of six sequence-tagged sites from the AZF region on Yq11, including sY84 and sY86 (AZFa), sY127 and sY134 (AZFb), sY254 and sY255 (AZFc). In addition, amplification of a pseudoautosomal region of Y chromosome (ZFY) and SRY (sY14) gene was used as internal control. Fertile male, female samples and deionizied water were used as positive, negative and blank controls, respectively. Size of amplification products is as follow: ZFY - $495 \mathrm{bp}$, SRY - 472 bp, sY254 - 400 bp, sY255 - 126 bp, sY84 320 bp, sY86 - 326 bp, sY134 - 301 bp, sY127 - 274 bp. The two multiplex PCR reactions were designed - A and B (Table 1). The reagents used to carry out the amplification reactions for the tested markers are presented in Table 2. PCR samples were analyzed on $2 \%$ agarose gel, stained with ethidium bromide, and visualized using ultraviolet transillumination. The samples that were detected to have a deletion were additionally confirmed by another PCR.

Table 1. Design of the primers and reaction mixtures used for screening of Yq microdeletions

\begin{tabular}{|c|c|c|}
\hline $\begin{array}{l}\text { Name of } \\
\text { Primer }\end{array}$ & Sequences of Primer & $\begin{array}{l}\text { Reaction mixtures containing } \\
\text { the respective primers }\end{array}$ \\
\hline $\mathrm{ZFX}-\mathrm{F}$ & $5^{\prime}-$ ACC $\mathbf{R}^{*}$ CT GTA CTA CTG ACT GTG ATT ACA C - 3' & $A$ and $B$ \\
\hline $\mathrm{ZFX}-\mathrm{R}$ & 5' - GCA CY*T CTT TGG TAT CY*G AGA AAG T - 3' & $A$ and $B$ \\
\hline $\mathrm{SRY}-\mathrm{F}$ & 5' -GAA TAT TCC CGC TCT CCG GA - 3' & $A$ and $B$ \\
\hline SRY - R & 5' - GCT GGT GCT TTC TTG AG - 3' & $A$ and $B$ \\
\hline $\mathrm{sY} 86-\mathrm{F}$ & $5^{\prime}$ - GTG ACA CAC AGA CTA TGC TTC - 3' & $\mathbf{A}$ \\
\hline sY86-R & 5' - ACA CAC AGA GGG ACA ACC CT - 3' & $\mathbf{A}$ \\
\hline sY127-F & 5' - GGC TCA CAA ACG AAA AGA AA - 3' & A \\
\hline sY127-R & 5' - CTG CAG GCA GTA ATA AGG GA - 3' & $\mathbf{A}$ \\
\hline sY254-F & 5' - GGG TGT TAC CAG AAG GCA AA - 3' & $\mathbf{A}$ \\
\hline sY254-R & 5' - GAA CCG TAT CTA CCA AAG CAG C - 3' & $\mathbf{A}$ \\
\hline sY84-F & 5' - AGA AGG GTC TGA AAG CAG GT - 3' & B \\
\hline sY84-R & 5' - GCC TAC TAC CTG GAG GCT TC - 3 & B \\
\hline sY134-F & 5' - GTC TGC CTC ACC ATA AAA CG - 3' & B \\
\hline sY134-R & 5' - ACC ACT GCC AAA ACT TTC AA - 3' & B \\
\hline sY255-F & 5' - GTT ACA GGA TTC GGC GTG AT - 3' & B \\
\hline sY255-R & 5' - CTC GTC ATG TGC AGC CAC - 3' & B \\
\hline
\end{tabular}

$* \mathbf{R}=\mathbf{A}+\mathbf{G}, \quad \mathbf{Y}=\mathbf{C}+\mathbf{T}$ 
Table 2. Content of the reaction mixture and concentration of the components used for screening of Yq microdeletions

\begin{tabular}{|c|c|c|c|c|c|}
\hline \multicolumn{4}{|c|}{ Components of the reaction mixture } & Concentration & Volume \\
\hline \multicolumn{4}{|c|}{ DNA } & $100 \mathrm{ng} / \mu \mathrm{l}$ & $1 \mu \mathrm{l}$ \\
\hline \multicolumn{4}{|c|}{ Primers ( mix A or mix B ) } & \multirow[t]{12}{*}{$*$} & \multirow[t]{12}{*}{$2.4 \mu \mathrm{l}$} \\
\hline Mix A & & & Mix B & & \\
\hline ZFY - F & $0.5 \mu \mathrm{l}$ & ZFY - F & $0.5 \mu \mathrm{l}$ & & \\
\hline ZFY - R & $0.5 \mu \mathrm{l}$ & ZFY - R & $0.5 \mu \mathrm{l}$ & & \\
\hline SRY - F & $0.2 \mu \mathrm{l}$ & SRY - F & $0.2 \mu \mathrm{l}$ & & \\
\hline SRY - R & $0.2 \mu \mathrm{l}$ & SRY - R & $0.2 \mu \mathrm{l}$ & & \\
\hline $254-F$ & $0.1 \mu \mathrm{l}$ & $86-F$ & $0.1 \mu \mathrm{l}$ & & \\
\hline $254-\mathbf{R}$ & $0.1 \mu \mathrm{l}$ & $86-\mathbf{R}$ & $0.1 \mu \mathrm{l}$ & & \\
\hline $84-F$ & $0.2 \mu \mathrm{l}$ & $134-F$ & $0.2 \mu \mathrm{l}$ & & \\
\hline $84-\mathbf{R}$ & $0.2 \mu \mathrm{ll}$ & $134-\mathbf{R}$ & $0.2 \mu \mathrm{l}$ & & \\
\hline $127-F$ & $0.2 \mu \mathrm{ll}$ & $255-F$ & $0.2 \mu \mathrm{l}$ & & \\
\hline $127-\mathbf{R}$ & $0.2 \mu \mathrm{l}$ & $255-\mathbf{R}$ & $0.2 \mu \mathrm{l}$ & & \\
\hline \multicolumn{4}{|c|}{ Buffer for thermostable DNA polymerase $\left(-\mathrm{MgCI}_{2}\right)$} & $10 \mathrm{X}$ & $2,5 \mu \mathrm{l}$ \\
\hline \multicolumn{4}{|c|}{$\mathrm{MgCI}_{2}$} & $(25 \mathrm{mM})$ & $2,5 \mu 1$ \\
\hline \multicolumn{4}{|c|}{ Nucleotide triphosphates } & $5 \mathrm{mM}$ & $2,0 \mu \mathrm{l}$ \\
\hline \multicolumn{4}{|c|}{ Taq - polymerase } & $5 \mathrm{U} / \mu \mathrm{l}$ & $0,3 \mu \mathrm{l}$ \\
\hline \multicolumn{4}{|c|}{$\mathrm{H}_{2} \mathrm{O}$} & $14,3 \mu \mathrm{l}$ & $14,3 \mu \mathrm{l}$ \\
\hline \multicolumn{4}{|c|}{ Total volume of the reaction mixture } & & $25 \mu \mathrm{l}$ \\
\hline
\end{tabular}

*Work concentration of any primer $20 \mathrm{pmol} / \mu \mathrm{l}$

\section{RESULTS}

Cytogenetic analysis showed that of 137 infertile men studied, 114 men (83.2\%) had a normal karyotype and 23 men had $(16.8 \%)$ abnormal karyotype. The frequencies of CA in two subgroups were: $20.7 \%(12 / 58)$ in patients with azoospermia and $13.9 \%(11 / 79)$ in patients with oligozoospermia. The detected CAs are presented in Table 3. Sex CAs were found in $12(8.8 \%)$ of all tested men: 6 (13.8\%) male with azoospermia and 3 men with oligozoospermia. Klinefeltar syndrome is the most frequent (75\%) of sex chromosome anomaly, established in $9(6.5 \%)$ of a total studied infertile men (6 men with azoospermia and 3 men with oligozoospermia). Autosomal CAs in the form of balanced chromosomal rearrangements (including 8 cases of translocations, 2 cases of inversions, and one polymorphism) were established in $11(8 \%)$ of all infertile patients. 
Table 3. Chromosomal abnormalities detected in 137 Bulgarian men with severe infertility

\begin{tabular}{|c|c|c|c|}
\hline $\begin{array}{l}\text { Indication /Degree of } \\
\text { infertility disorder }\end{array}$ & Chromosomal abnormality & $\begin{array}{l}\text { Number of patients } \\
\text { with abnormality }\end{array}$ & $\begin{array}{l}\text { Frequency of Chromo- } \\
\text { somal abnormalities (in \%) }\end{array}$ \\
\hline Azoospermia $/ \mathbf{N}=58$ men/ & $\begin{array}{l}\text { 47,XXY } \\
\text { 46,XY,del(Y)(q11.2-qter) } \\
\text { 46,XX SRY-positive male } \\
\text { 46,XY,der(13;14)(q10;q10) } \\
\text { 46,XY,t(2;14)(p13-p11) } \\
\text { 46,XY,inv(3)(q12-q23) }\end{array}$ & $\begin{array}{c}12 \\
6 \\
1 \\
1 \\
2 \\
1 \\
1\end{array}$ & $20.7 \%(12 / 58)$ \\
\hline Olygozoospermia $/ \mathrm{N}=79 \mathrm{men} /$ & $\begin{array}{l}\text { 47,XXY } \\
\text { 47,XXY[47]/48,XXXY[3] } \\
\text { 47,XYY } \\
\text { 46,XY,der(13;14)(q10;q10) } \\
\text { 46,XY, t(4;12)(q12;q24.3) } \\
\text { 46,XY, t (3;11)(q12-q23) } \\
\text { 46,XY, t (1;9)(p36-q34) } \\
\text { 46,XY, t (11;13)(p15-q12) } \\
\text { 46,XY, inv (4)(p16-q21) } \\
\text { 46,XY del (14 p) }\end{array}$ & $\begin{array}{c}\mathbf{1 1} \\
2 \\
1 \\
1 \\
1 \\
1 \\
1 \\
1 \\
1 \\
1 \\
1\end{array}$ & $13.9 \%(11 / 79)$ \\
\hline $\begin{array}{l}\text { Total in cases with severe } \\
\text { male infertility / } N=137 \text { men/ }\end{array}$ & & 23 & $16.8 \%(23 / 137)$ \\
\hline
\end{tabular}

In the current study of 109 studied infertile men, delYq were established in $6(5.5 \%)$ men, all of them with azoospermia (Table 4). Among these patients, three had deletions of AZFc, two had deletions of AZFb, and one had a deletion of $\mathrm{AZFb}+\mathrm{AZFc}$. In the last patient, delY
$\mathrm{AZFb}+\mathrm{AZFc}$ was visible in cytogenetic analysis $\operatorname{del}(\mathrm{Y})(\mathrm{q} 11.2$-qter). The frequency of delYq was $9.5 \%$ of in azoospermic subgroup. No microdeletions were detected in a subgroup of men with oligozoospermia.

Table 4. Frequency of the detected delYq according to the degree of infertility disorder

\begin{tabular}{|l|l|l|l|}
\hline $\begin{array}{l}\text { Degree of infertility } \\
\text { disorder }\end{array}$ & $\begin{array}{l}\text { Studied men } \\
\text { (Number) }\end{array}$ & $\begin{array}{l}\text { Yq microdeletions detected } \\
\text { (Number) }\end{array}$ & $\begin{array}{l}\text { Frequency of Yq } \\
\text { microdeletions (\%) }\end{array}$ \\
\hline Azoospermia & 63 & 6 & $9.5 \%$ \\
& & $\begin{array}{l}\text { AZFc } / 3 / \\
\text { AZFb /2/ } \\
\text { AZFb+AZFc/1/ }\end{array}$ & $4.8 \%$ \\
& & - & $0.16 \%$ \\
\hline $\begin{array}{l}\text { Severe Olygozoospermia } \\
\text { (sperm count }<5 \times 10 \% / \mathrm{ml}\end{array}$ & 46 & - & - \\
\hline Total & $\mathbf{1 0 9}$ & $\mathbf{6}$ & $\mathbf{5 . 5 \%}$ \\
\hline
\end{tabular}

If the frequencies of CA and delYq, established in with oligozoospermia. our study, were $16.8 \%$ and $5.5 \%$ respectively, the overall proportion of these genetic defects that we found in etiology of severe male infertility would be $22.3 \%$. The proportion of two genetic causes was higher $30.2 \%$ in a subgroup of males with azoospermia and $13.9 \%$ in males

\section{DISCUSSION}

Chromosomal abnormalities and $\mathrm{Y}$ chromosome microdeletions are considered to be the most common genetic causes of male infertility [7]. Based on the published 
in literature data, the overall frequency of CA in infertile males widely ranges from $2 \%$ to $28 \%$ (only $0.7 \%-1 \%$ in general male population) and the variation is mainly the result of different study design, patient group, ethnic background and others factors [4,7-12]. The review articles of Ferlin A. 2007 [13] and O'Flynn 2010 [2] estimate that the overall frequency ranges between $2 \%$ and $8-10 \%$ (with an average value of $5 \%$ ) and increases up to $15 \%$ in azoospermic males.

In our study, CAs were found in $16.8 \%$ of all investigated infertile men and $20.7 \%$ in the subgroup of patients with azoospermia. We established an overall frequency of CA that is similar to that reported in other studies $[11,12](11.6 \%$ and $22 \%$ respectively) with a desigh similar to ours. The much higher frequencies in our study may be are due to the preliminary selection of the studied patients: men with severe infertility (azoospermia or severe oligozoospermia) and exclusion in advance of more common non-genetic causes, factors that increase the probability to detect genetic causal factors for infertility.

In accordance with the literature $[2,8,9,13]$, in our study sex, CAs were more frequent in a subgroup of males with azoospermia $13.8 \%$, and Klinefeltar syndrome had the highest frequency of $10.3 \%$. The other CAs found in our cases with severe male infertility were balanced autosomal rearrangements more common established among oligozoospermic men $8.9 \%$. Along with fertile problems, CAs are associated with risk for abnormal offspring, therefore genetic counseling is recommended in all cases of detected CA in men.

Microdeletions of Y chromosome we detected in $5.5 \%$ of all tested infertile men and up to $9.5 \%$ in the subgroup of azoospermic men. The most common were deletions of $\mathrm{AZFc}$ region, in consistence with the literature [2, 4, 6, 10, 11, 14].

The overall frequency of delYq varies from 1 to $58 \%$ in different published studies. The frequency of delY is about $15-20 \%$ in azoospermic cases, $5-10 \%$ in cases with idiopathic severe oligizoospermia and $2-3 \%$ in men candidates for ICSI $[4,13]$. The variation in reported frequencies could be due to different patients selection criteria, sample size, used STS primers, ethical and geographical difference, other additional genetic backgrounds, environmental influences. Higher frequencies were found in studies using strict criteria for selection of patients, males with severe infertility as well as the study of cases with the preliminary exclusion of other more frequently causes for infertility disorder $[2,4,7,9,13,11-15]$.

Genetic abnormalities are thought to contribute to $15 \%-30 \%$ of severe male infertility $[1,3]$. In our study, the overall proportion of the two most common genetic factors (CA and delYq) was higher $30 \%$ in patients with azoospermia and $14 \%$ in men with oligozoospermia. The established overall proportion of genetic factors of $22 \%$ in cases of Bulgarian men with severe infertility is similar to the reported of Fu L. et al. 2012 [11], and Dada R. et al., 2006 [12] (19.8\% and 26.7\% respectively) in studies with design similar to ours.

\section{CONCLUSION}

- Chromosomal abnormalities and Yq microdeletions are important genetic factors in etiology of male infertility, accounting for about $22 \%$ of cases with severe infertility in Bulgarian men.

- Use of strict criteria for selection of the study group of infertile male increase the chance to find a genetic cause for infertility.

- Genetic testing should be a routine part of examinations in infertile males, providing helpful information about the cause of the problem and how to deal with it.

- Genetic counseling, in cases with identified genetic causes, allows assessment of possible genetic risks and provides an opportunity for the best choice of appropriate technique for assisted reproduction of the couple.

\section{REFERENCES:}

1. de Kretser DM. Male infertility. Lancet. 1997 Mar 15;349(9054):78790. [PubMed]

2. O'Flynn O'Brien KL, Varghese AC, Agarwal A. The genetic causes of male factor infertility: a review. Fertil Steril. 2010 Jan;93(1):1-12. [PubMed] [Crossref]

3. Boivin J, Bunting L, Collins JA, Nygren KG. International estimates of infertility prevalence and treatmentseeking: potential need and demand for infertility medical care. Hum Reprod. 2007 Jun;22(6):1506-12. [PubMed] [Crossref]

4. Suganthi R, Vijesh VV, Vandana N, Fathima Ali Benazir J. Y choromosomal microdeletion screening in the workup of male infertility and its current status in India. Int $J$ Fertil Steril. 2014 Jan;7(4):253-66. [PubMed]

5. Agarwal A, Mulgund A, Hamada A, Chyatte MR. A unique view on male infertility around the globe. Reprod Biol Endocrinol. 2015 Apr 26;13:37. [PubMed] [CrossRef]

6. Krausz C. Male infertility: pathogenesis and clinical diagnosis. Best Pract Res Clin Endocrinol Metab. 2011 Apr;25(2):271-85. [PubMed] [CrossRef]

7. Stouffs K, Seneca S, Lissens W. Genetic causes of male infertility. Ann Endocrinol (Paris). 2014 May; 75(2):109-11. [PubMed] [Crossref]
8. Van Assche E, Bonduell M, Tournaye H, Joris H, Verheyen G, Devroey $\mathrm{P}$, et al. Cytogenetic of infertile men. Hum Reprod. 1996 Dec;11 Suppl 4:1-24; discussion 25-6. [PubMed]

9. Balkan M, Tekes S, Gedik A. Cytogenetic and Y chromosome microdeletion screening studies in infertile males with Oligozoospermia and Azoospermia in Southeast Turkey. J Assist Reprod Genet. 2008 Nov-Dec; 25(11-12):559-65. [PubMed] [Crossref]

10. Naasse $\mathrm{Y}$, Charoute H, El Houate B, Elbekkay C, Razoki L, Malki A, et al. Chromosomal abnormalities and $\mathrm{Y}$ chromosome micro- 
deletions in infertile men from Morocco. BMC Urology. 2015 Sep 18;15:95. [PubMed] [Crossref]

11. Fu L, Xiong DK, Ding XP, Li C, Zhang LY, Ding M, et al. Genetic screening for chromosomal abnormalities and $\mathrm{Y}$ chromosome microdeletions in Chinese infertile men. J Assist Reprod Genet. 2012 Jun;29(6):521-7. [PubMed] [Crossref]

12. Dada R, Gupta NP, Kucheria K. Cytogenetic and molecular analysis of male infertility: Y chromosome deletion during nonobstructive azoospermia and severe oligozoospermia. Cell Biochem Biophys. 2006; 44(1):171-7. [PubMed] [Crossref]

13. Ferlin A, Raicu F, Gatta V, Zuccarello D, Palka G, Foresta C. Male infertility: role of genetic background. Reprod Biomed Online. 2007 Jun;14:734-45. [PubMed]

14. Rives N. Y chromosome microdeletions and alterations of sper- matogenesis, patient approach and genetic counseling. Ann Endocrinol (Paris). 2014 May;75(2):112-4. [PubMed] [Crossref]

15. Yousefi-Razin E, Nasiri MJ, Omrani MD. Frequency of Y Chromosome Microdeletions Among Iranian Infertile Men with Azoospermia and Severe Oligozoospermia: A Metaanalysis. J Reprod Infertil. 2016 OctDec;17(4):208-212. [PubMed]

Please cite this article as: Kovacheva K, Kotsev R, Emiliana Konova E, Rilcheva V, Kamburova Z, Simeonova M. Chromosomal abnormalities and Y chromosome microdeletions in Bulgarian male with azoospermia or severe oligospermia. J of IMAB. 2018 Oct-Dec;24(4):2217-2222. DOI: https://doi.org/10.5272/jimab.2018244.2217

Received: 27/06/2018; Published online: 23/10/2018

Address for correspondence:

Assoc. Prof. Katya Kovacheva, MD, PhD

Section of Medical Genetics, Medical University, Pleven,

1, St. Kliment Ohridski str., 5800 Pleven, Bulgaria.

E-mail: katiakovach@gmail.com 